\title{
Association between climatic variables and COVID-19 pandemic in National Capital Territory of Delhi, India
}

\author{
Omvir Singh ${ }^{1}$ (D) Pankaj Bhardwaj ${ }^{2}$. Dinesh Kumar ${ }^{3}$
}

Received: 6 July 2020 / Accepted: 23 September 2020 / Published online: 7 October 2020

(c) Springer Nature B.V. 2020

\begin{abstract}
Globally, since the end of December 2019, coronavirus disease (COVID-19) has been recognized as a severe infectious disease. Therefore, this study has been attempted to examine the linkage between climatic variables and COVID-19 particularly in National Capital Territory of Delhi (NCT of Delhi), India. For this, daily data of COVID-19 has been used for the period March 14 to June 11, 2020, (90 days). Eight climatic variables such as maximum, minimum and mean temperature $\left({ }^{\circ} \mathrm{C}\right)$, relative humidity $(\%)$, bright sunshine hours, wind speed $(\mathrm{km} / \mathrm{h})$, evaporation $(\mathrm{mm})$, and rainfall $(\mathrm{mm})$ have been analyzed in relation to COVID-19. To study the relationship among different climatic variables and COVID-19 spread, Karl Pearson's correlation analysis has been performed. The Mann-Kendall method and Sen's slope estimator have been used to detect the direction and magnitude of COVID-19 trends, respectively. The results have shown that out of eight selected climatic variables, six variables, viz. maximum temperature, minimum temperature, mean temperature, relative humidity, evaporation, and wind speed are positively associated with coronavirus disease cases (statistically significant at 95 and $99 \%$ confidence levels). No association of coronavirus disease has been found with bright sunshine hours and rainfall. Besides, COVID-19 cases and deaths have shown increasing trends, significant at $99 \%$ confidence level. The results of this study suggest that climatic conditions in NCT of Delhi are favorable for COVID-19 and the disease may spread further with the increasing temperature, relative humidity, evaporation and wind speed. This is the only study which has presented the analysis of COVID-19 spread in relation to several climatic variables for the most densely populated and rapidly growing city of India. Thus, considering the results obtained, effective policies and actions are necessary especially by identifying the areas where the spread rate is increasing rapidly in this megacity. The prevention and protection measures should be adopted aiming at to reduce the further transmission of disease in the city.
\end{abstract}

Keywords Coronavirus $\cdot$ Climate $\cdot$ Correlation $\cdot$ Trend $\cdot$ NCT of Delhi

Omvir Singh

ovshome@yahoo.com

Extended author information available on the last page of the article 


\section{Introduction}

Recently, coronavirus disease 2019 (COVID-19) has been recognized as an infectious disease far and wide. The World Health Organization (WHO) has acknowledged its spread as a public health emergency (WHO 2020). The outbreak of this pandemic has occurred in Wuhan city of Hubei Province, China in late December of 2019, when a case of unknown pneumonia has been testified (Zhu et al. 2020). The WHO has officially termed the coronavirus disease as COVID-19 pandemic. This pandemic has not differentiated between geography, ethnicity, religion, and politics and, therefore, has hit the world severely and unexpectedly. This pandemic has quickly spread first within China and then rapidly crossed the borders, infecting people across the world. Till July 06, 2020, the WHO has reported that the disease has significantly affected 216 countries, areas, or territories and has 11.32 million confirmed cases globally due to contact transmission with an average incubation period from 6 to 14 days. Of these confirmed cases, 5,32,340 have died (WHO 2020). Clinical findings pertaining to COVID-19 pandemic have reported that fever, pneumonia, coughing, and difficulty in breathing are some of the early symptoms, whereas it causes failure of kidney and even death in acute stage (Tosepu et al. 2020). The major preventive measures with regard to pandemic encompass physical distancing, regular washing of hands, and avoid the touching of nose, mouth, and eyes (WHO 2020). Remarkably, the majority of the global population has been frustrated and endangered owing to exponential increase in infection and mortalities (Asyary and Veruswati 2020). The pandemic has severely affected the supply of goods and services, people's lifestyle, health and education system, environment, daily routine, business, sports, religious, political, cultural, and economic activities. The global economic growth rate will witness a decline to the tune of $-3 \%$ in 2020 (Gopinath 2020).

So far, the influence of COVID-19 pandemic has been found more severe in the temperate countries (mid-latitudes) where the temperature has been observed considerably low $\left(0-15^{\circ} \mathrm{C}\right)$ in contrast to the warm tropical (low latitudes) and frigid polar (high latitudes) countries (Scafetta 2020). In the light of above, it will be logical to know whether geographical or environmental factors within a specific climatic zone are susceptible with regard to spread of COVID-19 pandemic or not. In past, many studies have established that the emergence and transmission of several infectious disease like pneumonia or influenza depend on climatic conditions, for example, temperature, rainfall, humidity, wind speed, pressure, sunshine, and evaporation (Dalziel et al. 2020). Likewise, many researchers have studied the association between different climatic variables and COVID19 pandemic transmission and revealed a significant positive relationships, resembling with the occurrence of past transmissible diseases (Tosepu et al. 2020; Bashir et al. 2020; Gupta et al. 2020a; Liu et al. 2020a, b; Ma et al. 2020; Sahin 2020; Xie and Zhu 2020). Remarkably, Shi et al. (2020) have reported a strong association among diurnal temperature and diurnal count of COVID-19 pandemic confirmed patients in China and suggested that temperature above $8-10{ }^{\circ} \mathrm{C}$ would lead to a decline in confirmed cases. Similarly, a rise in $1{ }^{\circ} \mathrm{C}$ temperature would result a decline in diurnal confirmed COVID-19 pandemic cases in Brazil (Prata et al. 2020). The other way around, no consistent relationships with the cumulative cases of COVID-19 pandemic in relation to humidity (Shi et al. 2020) and the warmer mean, minimum and maximum temperature have been witnessed (Xie and Zhu 2020; Briz-Redón and Serrano-Aroca 2020). Besides, several researchers have indicated a reduction in number of COVID-19 cases and deaths with increase in temperature and relative humidity worldwide (Wang et al. 2020a; Bannister-Tyrrell et al. 2020; Ma et al. 
2020; Wu et al. 2020). Overall, the scientific community and people have a belief that an increase in temperature and humidity will reduce the number of COVID-19 cases.

India with its 1.3 billion population is highly overpopulated and is constantly at high risk due to COVID-19 pandemic outbreaks (Minhas 2020). As of July 06, 2020, India, after USA, and Brazil have the maximum COVID-19 pandemic confirmed cases in the world in the wake of striking its first case on January 30, 2020 (WHO 2020). According to Ministry of Health and Family Welfare, India have confirmed a total of 6,97,413 cases, 4,24, 432 recoveries, and 19,693 deaths all over India till July 06, 2020, with an increase of over 20,000 confirmed new cases per day. Besides, suicides among people on account of unwarranted panic of contacting and touching with coronavirus-infected patients have been recorded (Goyal et al. 2020). Till July 06, 2020, Maharashtra has the largest number of confirmed cases $(2,06,619)$ accompanied by Tamil Nadu $(1,11,151)$ and National Capital Territory of Delhi (NCT of Delhi) $(99,444)$. Further, the disease has been reported in majority of districts in the country, though initially the degree of spread is small than other nations but currently showing the signs of community spread at several locations.

Apart from the above, several researchers have focused on COVID-19 pandemic in relation to climatic variables in India (Das et al. 2020; Dimri et al. 2020; Ghosh et al. 2020; Gupta and Pradhan 2020; Gupta et al. 2020a, b; Meraj et al. 2020; Roy 2020; Vinoj et al. 2020). However, most of the studies have used short period of data and provided the association of COVID-19 with two variables, i.e., temperature and humidity. In India, so far, no comprehensive academic study has been reported, which can guide researchers and policy makers about the influences of climatic conditions on the extension of COVID19 pandemic in the megacities. Therefore, to fill this research gap, this study has been attempted to provide scientific evidences regarding the spread of COVID-19-infected cases in relation to various climatic variables over NCT of Delhi, a megacity in India. The present study has utilized the 3-month-long period data from March 14 to June 11, 2020 (90 days). This is the only study which has presented the analysis of COVID-19 pandemic in relation to several climatic variables for the most densely populated and rapidly growing city of India. The study will provide a holistic insight to researchers, academicians and health policy makers to study the relationship of COVID-19 in relation to several climatic variables. The findings of this study will also provide a base for future studies regarding climatic variables and COVID-19 pandemic transmission over other megacities of India located in tropical and sub-tropical zones.

\section{Study area}

The study area, NCT of Delhi, extends between $76^{\circ} 50^{\prime} \mathrm{E}$ to $77^{\circ} 20^{\prime} \mathrm{E}$ longitudes and $28^{\circ} 24^{\prime} \mathrm{N}$ to $28^{\circ} 05^{\prime} \mathrm{N}$ latitudes and covers an area of approximately $1483 \mathrm{~km}^{2}$ (Fig. 1). Being the national capital territory, it is among the vital centers for business, industries and commerce in north India. It is also known as the legislative and second economic metropolis of the country. It is the largest urban agglomeration of the country with a population of about 16.8 million. According to the census of India 2011, the density of population of NCT of Delhi is 11,297 persons $/ \mathrm{km}^{2}$, which is highest in the country. The decadal growth rate of population has been found about $21 \%$. Delhi has been growing by approximately 1000 persons every day for a number of years. Further, migration is approximately 1.3 times of the natural growth in NCT of Delhi (Singh and Shukla 2005). The urban population is approximately $97.5 \%$ of the total population. The average annual 


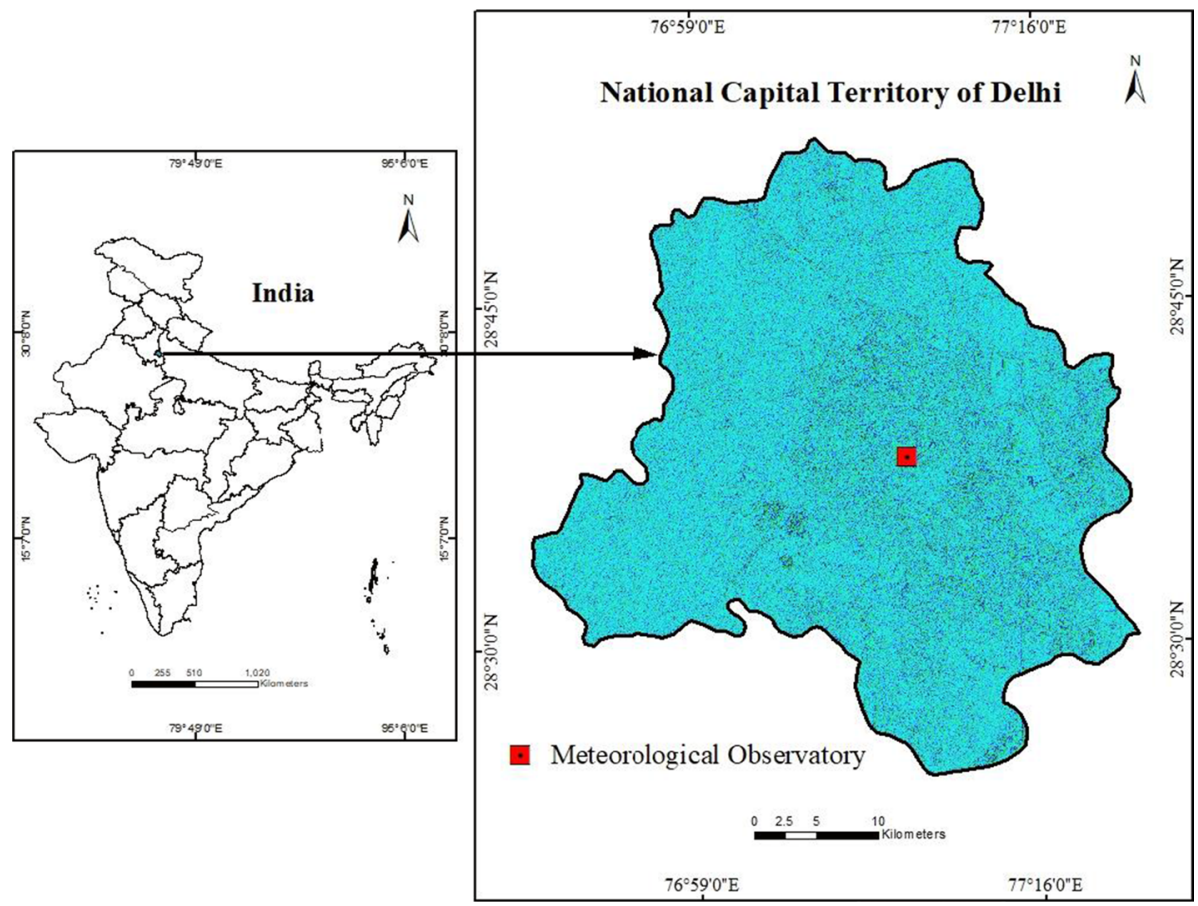

Fig. 1 Map showing the location of NCT of Delhi, India Source: Prepared by authors

growth rate of urban population is about $2.38 \%$ (GoI 2019). Overall, its growth is higher than growth rate of other cities in India. Apart from this, the NCT of Delhi is characterized by continental climate with warm and dry summers, and cold and dry winters. During summers, the maximum temperature reaches up to $47{ }^{\circ} \mathrm{C}$, whereas during winters, it drops to about $5{ }^{\circ} \mathrm{C}$ (Kumar et al. 2017). Monsoon season (June-September) accounts approximately $80 \%$ of total annual rainfall in the city (Perrino et al. 2011).

\section{Data and methods}

\subsection{Data collection}

For this study, daily data between March 14 to June 11, 2020, (90 days) with respect to prevalence of COVID-19 pandemic corresponding to NCT of Delhi has been retrieved from a source openly accessible through the https://www.covid19india.org/link, as this dataset provides the detailed information of COVID-19 without any gap for the study period. In this study, the initial date, i.e., March 14, 2020, has been chosen because NCT of Delhi has been identified for its first confirmed COVID-19 pandemic case on this day. The COVID19 pandemic data on the website are preserved and maintained by a group of volunteers and can be downloaded free of cost. The volunteers have extracted and homogenized the COVID-19 pandemic statistics from various internet references associated both with government and independent organizations. The dataset has comprised of the diurnal 
occurrence of COVID-19 pandemic confirmed cases, active cases, deceased and test conducted. However, in this study, total confirmed cases and deceased data has been considered as the values of these two variables have been found consistent throughout the study period.

Apart from the COVID-19 pandemic transmission data, the daily climatic data with respect to eight selected climatic variables for the same period (March 14 to June 11, 2020) have been procured from the bona fide internet site of ICAR-Indian Agricultural Research Institute, New Delhi (www.iari.res.in). In the present study, the selected climatic variables have consisted of maximum, minimum and mean temperature $\left({ }^{\circ} \mathrm{C}\right)$, relative humidity $(\%)$, bright sunshine hours, wind speed $(\mathrm{km} / \mathrm{h})$, evaporation $(\mathrm{mm})$ and rainfall $(\mathrm{mm})$. The climatic variables data has been found consistent without any gap during the study period.

\subsection{Data analysis}

The collected data have been analyzed by using Microsoft Excel Spreadsheet and presented in tabular form and graphs. The values of various COVID-19 confirmed cases and deceased have been found highly dynamic and changed rapidly every day. Thus, the data has also been analyzed separately for 15 days intervals. The monthly averages of different climatic variables have been computed by using their daily values from March 14 to June 11, 2020. Recently, correlation analysis has been extensively used to associate COVID-19 pandemic confirmed cases with climatic variables (Bashir et al. 2020; Ma et al. 2020; Prata et al. 2020). Therefore, to study the relationship among different climatic variables and COVID-19 pandemic confirmed cases, Karl Pearson's correlation analysis has been performed by employing the Statistical Package for the Social Sciences. The nonparametric Mann-Kendall test (Mann 1945; Kendall 1975) has been applied to detect the trends in the daily data of COVID-19. The magnitude of trends has been estimated by Sen's slope estimator (Sen 1968). The presence of statistically significance has been considered at 95 and $99 \%$ level of confidence.

\section{Results and discussion}

\subsection{Description of COVID-19 and meteorological parameters}

Figure 2 exhibits the daily count of COVID-19 pandemic confirmed victims and deceased persons along with their cumulative numbers. The figure displays that the COVID-19 pandemic cases has been very less up to March 28 in NCT of Delhi. However, from March 29,2020 , a sharp rise in the count of COVID-19 pandemic patients has been witnessed. To represent a comprehensive picture of COVID-19 pandemic spread, the 90-day study period (March 14-June 11, 2020) has been divided into 6 periods of 15 days each. During March 14-28, March 29 to April 12, April 13-27, April 28 to May 12, May 13-27, and May 28 to June 11 , a total of 49, 1105, 1954, 4531, 7618, and 19,430 COVID-19 pandemic cases (total 34,687) have been reported in the city, respectively. Only during May 28 to June 11, 2020, approximately 56\% confirmed cases and $72 \%$ deceased cases have been reported. Also, the cumulative number of deceased persons has been increasing rapidly in the NCT of Delhi. The results of trend test have shown significant increasing trends in the COVID19 cases and deaths, significant at $99 \%$ confidence level. 

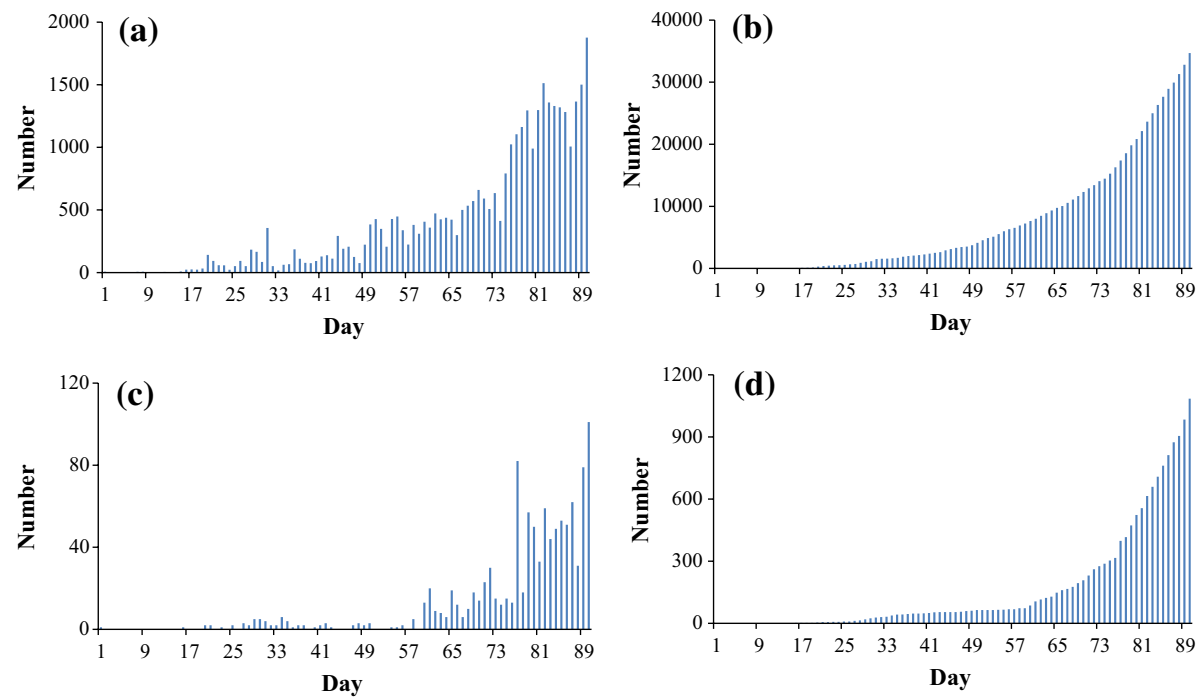

Fig. 2 a Daily number of cases confirmed, $\mathbf{b}$ cumulative cases, $\mathbf{c}$ daily deceased and $\mathbf{d}$ cumulative deceased due to COVID-19 during 90 days period from March 14-June 11, 2020, in NCT of Delhi, India
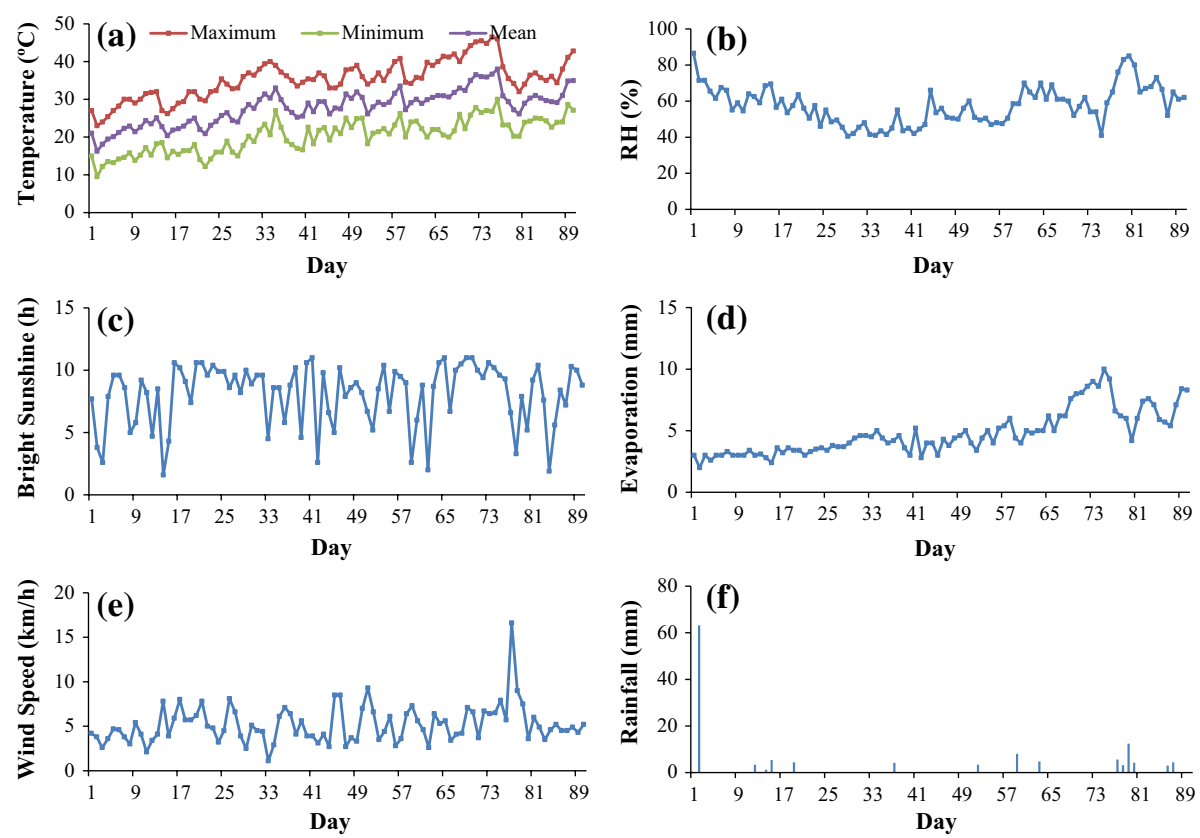

Fig. 3 Daily pattern of selected meteorological parameters a temperature, b RH, c bright sunshine, d evaporation, $\mathbf{e}$ wind speed and $\mathbf{f}$ rainfall during 90-day period from March 14-June 11, 2020, in NCT of Delhi, India 
Moreover, Fig. 3 exhibits the daily pattern of climatic variables during 90 days period from March 14 to June 11, 2020, over NCT of Delhi. A rise in temperature (maximum, minimum, and mean), relative humidity, and evaporation has been observed from March 14 to June 11, 2020, in NCT of Delhi. Also, wind speed has shown slight increase with large fluctuations. Bright sunshine hours have shown almost constant pattern, whereas almost negligible rainfall has been experienced during this period. During 90-day period, the mean temperature has been recorded as $27.8^{\circ} \mathrm{C}$ (lowest mean temperature $16.2^{\circ} \mathrm{C}$ and highest mean temperature $38.0^{\circ} \mathrm{C}$ ), mean maximum temperature has been $35.3^{\circ} \mathrm{C}$ (lowest maximum temperature $23{ }^{\circ} \mathrm{C}$ and highest maximum temperature $46.5{ }^{\circ} \mathrm{C}$ ) and mean minimum temperature has been experienced as $20.3{ }^{\circ} \mathrm{C}$ (lowest minimum temperature $9.5^{\circ} \mathrm{C}$ and highest minimum temperature $30.0^{\circ} \mathrm{C}$ ). The mean relative humidity has been observed to be $57.5 \%$ (maximum $86.5 \%$ and minimum $40.5 \%$ ). The mean bright sunshine has been recorded as $8.1 \mathrm{~h}$ (maximum $11.0 \mathrm{~h}$ and minimum, $1.6 \mathrm{~h}$ ), whereas the mean evaporation has been $4.8 \mathrm{~mm}$ (highest $10.0 \mathrm{~mm}$ and lowest $2.0 \mathrm{~mm}$ ). The mean wind speed has been measured as $5.2 \mathrm{~km} / \mathrm{h}$ (maximum $16.6 \mathrm{k} \quad \mathrm{m} / \mathrm{h}$ and minimum $1.1 \mathrm{~km} / \mathrm{h}$ ). Similarly, the mean rainfall has been gauged to the tune of $1.5 \mathrm{~mm}$ (maximum $63.2 \mathrm{~mm}$ and minimum $0 \mathrm{~mm})$.

\subsection{Correlation between climatic variables and COVID-19 pandemic}

The association among selected climatic variables and COVID-19 pandemic cases has been demonstrated in Fig. 4 and Table 1. A strong positive relationship of maximum temperature, minimum temperature and mean temperature with the count of COVID-19 pandemic confirmed victims and deceased persons (significant at $99 \%$ confidence level) has been witnessed. It indicates that the count of COVID-19 pandemic confirmed patients and deaths have increased with increasing temperature in NCT of Delhi. These results are in agreement with Gupta and Pradhan (2020), who have observed that the COVID19 cases are likely to increase with increasing air temperature in India; however, the role of humidity is not clear. Gupta et al. (2020b) have examined the climatic records of air temperature, rainfall, actual evapotranspiration, solar radiation, specific humidity, wind speed with topographic altitude and population density and suggests that comparatively hot and dry regions in lower altitude of the Indian territory are more prone to the infection by COVID-19 transmission. Tosepu et al. (2020) have also shown a significant positive association among COVID-19 pandemic victims and mean temperature in Jakarta, Indonesia. Bashir et al. (2020) have observed a noteworthy positive correlation of mean and minimum temperature with COVID-19 pandemic cases in New York city of USA. Interestingly, the results of present study have been found consistent with Tosepu et al. (2020) and Bashir et al. (2020). Benedetti et al. (2020) have not found a significant correlation between average monthly high temperatures and number of deaths per million people in the month of March. However, a statistically significant inverse correlation has been observed in the month of April between average monthly high temperatures $(p=0.0043)$ and latitude $(p=0.0253)$ with number of deaths per million people. They have also observed a statistically significant correlation between population density and number of deaths per million people. Prata et al. (2020) have shown a negative association among the temperature and COVID-19 pandemic confirmed victims in tropical cities of Brazil. Several other studies have also shown a negative link within COVID-19 cases and temperature for different parts in the world (Sahin 2020; Núñez-Delgado 2020; Zhu and Xie 2020). 

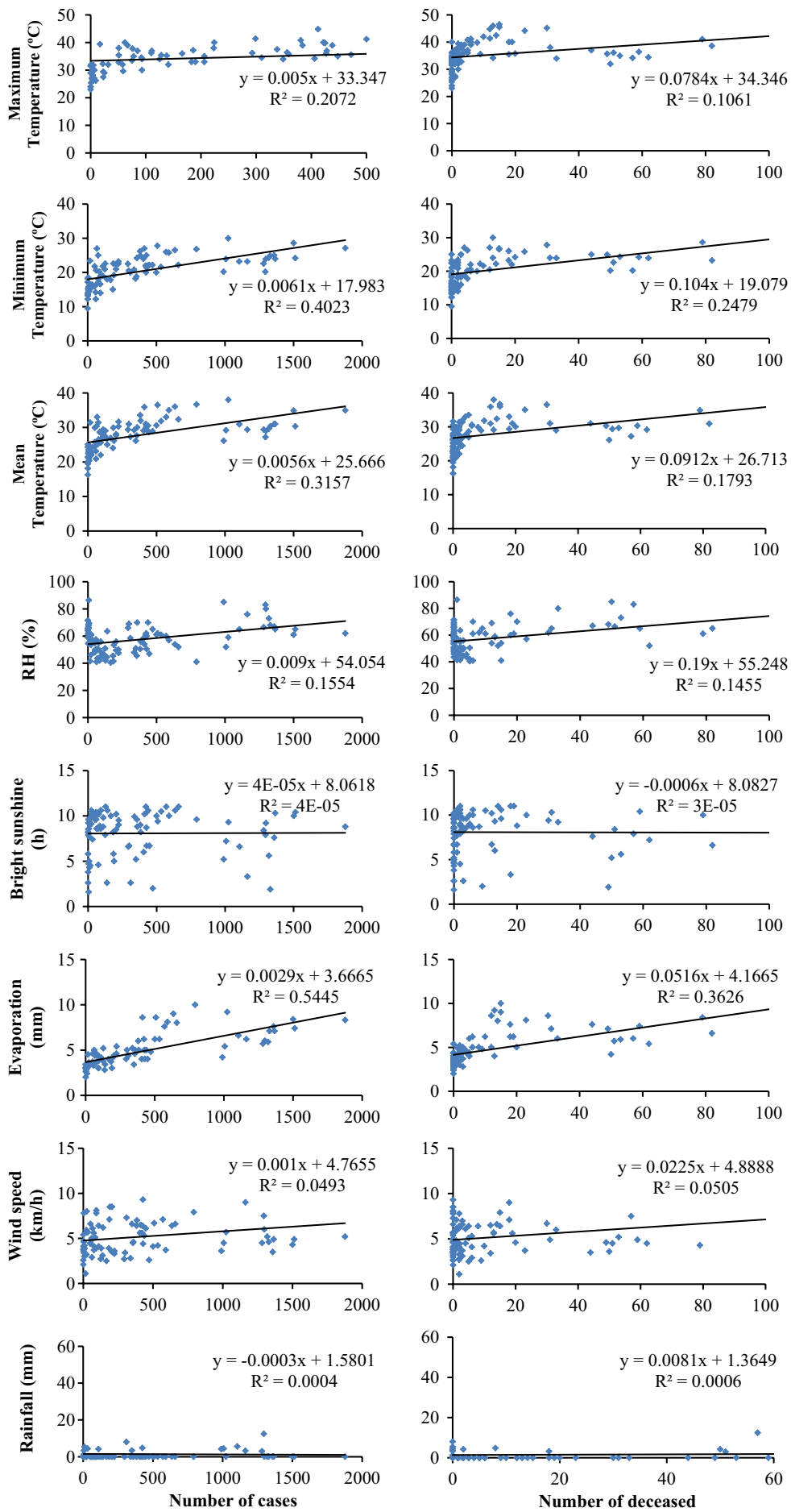

Fig. 4 Relationship of number of cases and deceased with different meteorological parameters during 90 days period from March 14-June 11, 2020, in NCT of Delhi, India 
Table 1 Correlation between number of confirmed COVID-19 cases and deceased with different meteorological parameters during 60-day period from March 14-June 11, 2020, in NCT of Delhi, India

\begin{tabular}{lcc}
\hline Meteorological parameters & Cases & Deceased \\
\hline Maximum temperature $\left({ }^{\circ} \mathrm{C}\right)$ & $0.455^{\mathrm{a}}$ & $0.326^{\mathrm{a}}$ \\
Minimum temperature $\left({ }^{\circ} \mathrm{C}\right)$ & $0.634^{\mathrm{a}}$ & $0.498^{\mathrm{a}}$ \\
Mean temperature $\left({ }^{\circ} \mathrm{C}\right)$ & $0.562^{\mathrm{a}}$ & $0.423^{\mathrm{a}}$ \\
Relative humidity $(\%)$ & $0.394^{\mathrm{a}}$ & $0.381^{\mathrm{a}}$ \\
Bright sunshine $(\mathrm{h})$ & 0.007 & -0.005 \\
Evaporation $(\mathrm{mm})$ & $0.738^{\mathrm{a}}$ & $0.602^{\mathrm{a}}$ \\
Wind speed $(\mathrm{km} / \mathrm{h})$ & $0.222^{\mathrm{b}}$ & $0.225^{\mathrm{b}}$ \\
Rainfall $(\mathrm{mm})$ & -0.020 & 0.025 \\
\hline
\end{tabular}

${ }^{\text {a }}$ Significant at $99 \%$ confidence level

${ }^{\mathrm{b}}$ Significant at $95 \%$ confidence level

Apart from the above, a positive correlation has been observed between relative humidity and COVID-19 pandemic confirmed cases and deceased (Table 1). These results are not consistent with Gupta et al. (2020a), who have witnessed the maximum transmission of confirmed COVID-19 pandemic cases within the states having wet and extremely wet climatic conditions. However, Oliveiros et al. (2020) have discovered a significant affirmative relation between COVID-19 pandemic spread and temperature, although a negative relationship has been identified with humidity in China. In addition, Sahin (2020) has shown an inconsistent negative relationship among humidity and COVID-19 pandemic transmission in Turkey. Bashir et al. (2020) have shown a non-significant negative correlation among humidity and COVID-19 pandemic confirmed cases for New York city of USA. Ma et al. (2020) have reported a negative relation among humidity and COVID-19 pandemic victims in Wuhan region of China. Also, a positive correlation among the evaporation and count of COVID-19 pandemic confirmed victims and deceased has been observed over NCT of Delhi.

Further, a positive correlation has been witnessed among COVID-19 pandemic confirmed and deceased cases with wind speed. However, the value of correlation has been found weak (Table 1). Similarly, Sahin (2020) has shown that the count of COVID19 pandemic victims surges with an increase in wind speed in Turkey. Islam et al. (2020) have shown inverse relationship of COVID-19 incidences with the temperature, humidity and wind speed world over. Adhikari and Yin (2020) have found that cloud cover, precipitation, and wind data are significantly associated with one-day lagged COVID-19 confirmed cases in Queens, New York. Contrastingly, Bashir et al. (2020) and Oliveiros et al. (2020) have not observed any correlation of COVID-19 pandemic spread with wind speed in China. Abdollahi and Rahbaralam (2020) have also witnessed a weak correlation of wind speed with COVID-19 in Spain. Again, rainfall has not been found associated with COVID-19 pandemic spread in NCT of Delhi (Table 1), which has been found consistent with the results reported by Tosepu et al. (2020). Raina et al. (2020) have shown that the countries with higher number of cases have cold weather. These are also the countries with low humidity which could be favoring the transmission and survival of COVID-19. The bright sunshine hours have not shown any association with the COVID-19 pandemic spread in NCT of Delhi. Likewise, Asyary and Veruswati (2020) have not observed any noticeable trend of sunlight exposure with the transmission rate, but reported a significant recovery rate under sunlight exposure in 
Indonesia. Gupta et al. (2020b) have shown a significant positive correlation between high solar radiations during daytime and COVID-19 transmission in India.

Interestingly, Wang et al. (2020b) and Araujo and Naimi (2020) have reported a lower survival rate of COVID-19 at higher temperatures and humidity. Middle East respiratory syndrome-related coronavirus cases have also shown an increase with high temperatures, coupled with high ultraviolet index, low wind speeds, and low relative humidity (Altamimi et al. 2019). Harmooshi et al. (2020) have observed that the COVID-19 can survive for up to 9 days at $25^{\circ} \mathrm{C}$, and if this temperature rises to $30{ }^{\circ} \mathrm{C}$, its lifespan will be shorter. Likewise, the COVID-19 is sensitive to humidity, and lifespan of viruses in 50\% humidity is longer than that of $30 \%$. Bu et al. (2020) have concluded that a temperature range of $13-19{ }^{\circ} \mathrm{C}$ and humidity of $50-80 \%$ are suitable for the survival and transmission of COVID-19. Yuan et al. (2020) have presented a comprehensive review on the impact of temperature and humidity on the transmission of COVID-19. Ujiie et al. (2020) have observed higher infectivity of COVID-19 pandemic patients during the winter season in Japan. Iqbal et al. (2020) have shown that most of the countries located in the relatively lower temperature region have shown a rapid increase in the COVID-19 cases than the countries located in the warmer climatic regions despite their better socioeconomic conditions. They identified that the regional meteorological parameters (aerosols, maximum and minimum temperature, day length, etc.) are among the contributors to the fast spread of coronavirus over most countries of the world. Shahzad et al. (2020) have witnessed that the increase in average temperature and bad air quality have significantly enhanced the COVID-19 new cases in all regions of Spain. Interestingly, Yao et al. (2020) have not shown any relationship between transmission of COVID-19 pandemic cases and temperature in Chinese cities. Ahmadi et al. (2020) have performed the sensitivity analysis and shown a direct relationship with the infection outbreak with population density, intraprovincial movement, whereas the areas with low values of wind speed, humidity, and solar radiation exposure to a high rate of infection that support the virus's survival. The correlation has disapproved their initial hypothesis that the extensive spread of COVID-19 may be limited by temperature and humidity.

Additionally, Xie and Li (2020) have found a positive correlation of population density and old-age people $(65+)$ with both the infection and mortality rates of COVID-19 in USA. Moreover, the counties that are percentage of rural, farm-dependent, or miningdependent population have high mortality rate of COVID-19, which may be attributed to the poor preparedness and medical systems in rural areas for the COVID-19 infection. This finding should be alarming since rural areas have limited medical resources to respond to this pandemic and treat COVID-19 patients. Vardavas and Nikitara (2020) and Liu et al. 2020a, b have found a negative association between percentage of smokers with the infection rate of COVID-19. However, other studies showed that smoking could worsen the health outcomes of COVID-19 patients (Vardavas and Nikitara 2020; Liu et al. 2020a, b). Sarmadi et al. (2020) have shown the higher COVID-19 cases and deaths rate per lakh population over the northern areas of the globe, including some parts of North America and approximately the entire Asia and Europe which are located in higher latitudes and have a colder climate and better socioeconomic conditions. The higher rates of COVID-19 cases and deaths over these areas could be related to the availability of diagnostics kits and health care facilities ( $\mathrm{Bi}$ et al. 2020). In addition, both colder climate and more densely populated areas could contribute to the spread of the disease in European and Asian megacities (Xie and Zhu 2020; Sajadi et al. 2020). Sannigrahi et al. (2020) have found a heterogeneous distribution of the COVID-19 confirmed cases and deaths across Europe. This uneven distribution could be attributed to many corresponding factors, including 
demography, climatic, cultural, or socio-economic differences among the countries. For both COVID-19 cases and deaths, the maximum records (actual values) have documented in the western European region (Spain, Italy, France, Germany, UK, Belgium, the Netherlands). The cases and deaths have been found lower (actual values) in the Eastern (Romania, Bulgaria, Greece, Estonia, Latvia, Lithuania) and Northern European region (Norway, Finland, Sweden). This can be attributed to the sociodemographic composition of these countries as Italy has the second oldest population (23\%) in the world and the oldest in Europe (population ages 65 and above). A study on COVID-19 patients from China and other countries showed that the older age group (above 60 years) had significantly higher death rate than the younger age group (below 60 years) (Verity et al. 2020). Mahajan and Kaushal (2020) have noticed that among all confirmed cases, about 60\% cases are of 20-49 age (median age of Indian COVID-19 patients is 39) which is working age in India and $76 \%$ cases are reported for men.

Ghosh et al. (2020) have observed that the major COVID-19 outbreak clusters are located in western and northern India and they are associated with major cities. Besides, approximately $42 \%$ people sustain their life in slum area in India, and they have no option to maintain social distancing rule due to their unhygienic and congested ambience. Manzak and Manzak (2020) have observed that the counties having high percentage of African American black populations show a high infection rate and high mortality in USA. Remarkably, the temperature, hours of sunshine, and white population percentage has a non-significant negative correlation with COVID-19. Das et al. (2020) have highlighted that the risks of COVID-19 tend to be higher in areas with low socioeconomic status over the northeastern part of Chennai megacity. Bhopal and Bhopal (2020) have examined the sex differential in the COVID-19 mortality and found that the male to female mortality sex ratio is 1.4 per 1,00,000 population over northwestern Europe, however, ratio is not equal at all ages.

\section{Conclusions}

In the present study, an attempt has been made to examine the association between climatic conditions and COVID-19 pandemic transmission victims over NCT of Delhi. The daily data of COVID-19 and eight climatic variables such as maximum, minimum and mean temperature, relative humidity, bright sunshine hours, wind speed, evaporation, and rainfall have been analyzed for the period March 14 to June 11, 2020 (90 days). To study the relationship among different climatic variables and COVID-19, Karl Pearson's correlation analysis has been performed. The Mann-Kendall method and Sen's slope estimator have been used to detect the direction and magnitude of COVID-19 trends, respectively. The analyses have shown that the COVID-19 is significantly associated with the climatic variables over the NCT of Delhi. The COVID-19 pandemic spread is positively related with the maximum temperature, minimum temperature and mean temperature, relative humidity, evaporation and wind speed. No link amid bright sunshine hours and rainfall has been witnessed with the COVID-19 pandemic spread in NCT of Delhi. Apart from this, COVID-19 cases and deaths have shown increasing trends, significant at $99 \%$ confidence level.

The finding of this study may represent the impact of climatic variables on the highdensity cities located in a warmer tropical climate. This study will also provide a base for other studies regarding climatic variables and COVID-19 pandemic transmission 


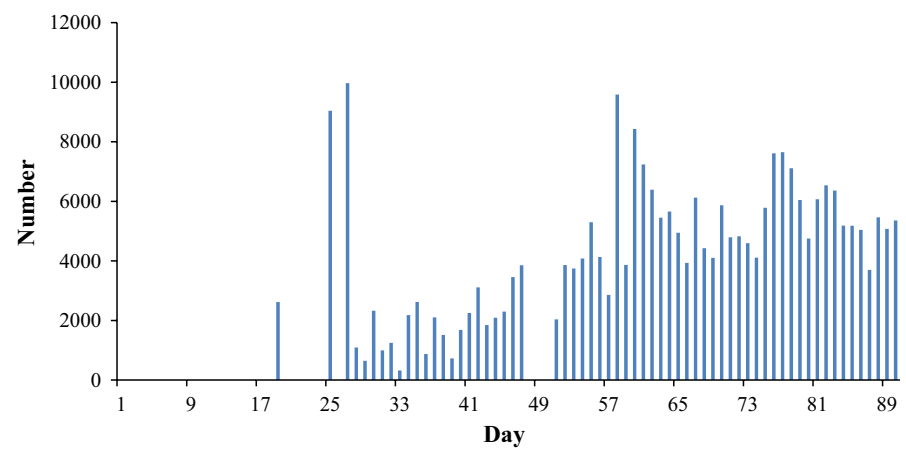

Fig. 5 Daily number of COVID-19 test conducted during 90 days period from March 14-June 11, 2020, in NCT of Delhi, India

over other megacities of India located in subtropical zone. These results may be useful for researchers and health policy-makers. Despite this, the current study may have some limitations. For example, these results are based on only one city. Also, a sharp increase in count of COVID-19 pandemic confirmed patients may be anomalously due to an increase in number of tests conducted during the last 30 days of this study than the initial outbreak of pandemic in NCT of Delhi (Fig. 5). Also, this study has not considered the non-climatic factors such as density of population, population by age-group, sociocultural factors, movement of people, urban-rural settings, gender, education and economic level, lifestyles and the size of household. These factors can help to transmit this disease. Therefore, further studies are needed on these shortcomings.

Acknowledgements The authors sincerely thank both the data sources for giving access to relevant data which has been used in this research. The authors sincerely thank the anonymous reviewers for critical comments and constructive suggestions, which improved the overall quality of the manuscript.

\section{Compliance with ethical standards}

Conflict of interest We have no conflicts of interest to disclose.

\section{References}

Abdollahi, A., \& Rahbaralam, M. (2020). Effect of temperature on the transmission of COVID-19: A machine learning case study in Spain. medRxiv, https://doi.org/10.1101/2020.05.01.20087759.

Adhikari, A., \& Yin, J. (2020). Short-term effects of ambient ozone, PM 2.5, and meteorological factors on COVID-19 confirmed cases and deaths in Queens, New York. International Journal of Environmental Research and Public Health, 17, 4047. https://doi.org/10.3390/ijerph17114047.

Ahmadi, M., Sharifi, A., Dorosti, S., Ghoushchi, S. J., \& Ghanbari, N. (2020). Investigation of effective climatology parameters on COVID-19 outbreak in Iran. Science of the Total Environment, 729, 138705. https://doi.org/10.1016/j.scitotenv.2020.138705.

Araujo, M. B., \& Naimi, B. (2020). Spread of SARS-CoV-2 Coronavirus likely to be constrained by climate. medRxiv, https://doi.org/10.1101/2020.03.12.20034728.

Asyary, A., \& Veruswati, M. (2020). Sunlight exposure increased COVID-19 recovery rates: A study in the central pandemic area of Indonesia. Science of the Total Environment, 729, 139016. https://doi. org/10.1016/j.scitotenv.2020.139016. 
Bannister-Tyrrell, M., Meyer, A., Faverjon, C., \& Cameron, A. (2020). Preliminary evidence that higher temperatures are associated with lower incidence of COVID-19, for cases reported globally up to 29th February 2020. medRxiv https://doi.org/10.1101/2020.03.18.200367312020.2003.2018.20036731.

Bashir, M. F., Ma, B., Bilal Komal, B., Bashir, M. A., Tan, D., \& Bashir, B. (2020). Correlation between climate indicators and COVID-19 pandemic in New York, USA. Science of the Total Environment, 728, 138835. https://doi.org/10.1016/j.scitotenv.2020.138835.

Benedetti, F., Pachetti, M., Marini, B., Ippodrino, R., Gallo, R. C., Ciccozzi, M., et al. (2020). Inverse correlation between average monthly high temperatures and COVID-19-related death rates in different geographical areas. Journal of Translational Medicine, 18, 251. https://doi.org/10.1186/s12967-02002418-5.

Bhopal, S. S., \& Bhopal, R. (2020). Sex differential in COVID-19 mortality varies markedly by age. The Lancet, 39, 532-533. https://doi.org/10.1016/S0140-6736(20)31748-7.

Bi, Q., Wu, Y., Mei, S., Ye, C., Zou, X., Zhang, Z., et al. (2020). Epidemiology and transmission of COVID19 in 391 cases and 1286 of their close contacts in Shenzhen, China: A retrospective cohort study. The Lancet Infectious Diseases, 20, 911-919. https://doi.org/10.1016/S1473-3099(20)30287-5.

Briz-Redón, A., \& Serrano-Aroca, A. (2020). A spatio-temporal analysis for exploring the effect of temperature on COVID-19 early evolution in Spain. Science of the Total Environment, 728, 138811. https:// doi.org/10.1016/j.scitotenv.2020.138811.

Bu, J, Peng, D, Xiao, H, Yue, Q., Han, Y., Lin, Y., Hu, G.,\&Chen, J. (2020). Analysis of meteorological conditions and prediction of epidemic trend of 2019-nCoV infection in 2020. medRxiv. https://doi. org/10.1101/2020.02.13.20022715.

Dalziel, B. D., Kissler, S., Gog, J. R., Viboud, C., Bjornstad, O. N., Metcaff, C. J. E., et al. (2020). Urbanization and humidity shape the intensity of influenza epidemics in U.S cities. Science, 362, 75-79. https ://doi.org/10.1126/science.aat6030.

Das, A., Ghosh, S., Das, K., Basu, T., Das, M., \& Dutta, I. (2020). Modeling the effect of area deprivation on COVID-19 incidences: A study of Chennai megacity, India. Public Health, 185, 266-269. https:// doi.org/10.1016/j.puhe.2020.06.011.

Dimri, V. P., Ganguli, S. S., \& Srivastava, R. P. (2020). Understanding trend of the Covid-19 fatalities in India. Journal of the Geological Society of India, 95, 637-639. https://doi.org/10.1007/s1259 4-020-1492-2.

Ghosh, K., Sengupta, N., Manna, D., \& De, S. K. (2020). Inter-state transmission potential and vulnerability of COVID-19 in India. Progress in Disaster Science. https://doi.org/10.1016/j.pdisas.2020.100114.

GoI. (2019). Handbook of urban statistics. Ministry of Housing and Urban Affairs. Government of India. http://mohua.gov.in/pdf/5c80e2225a124Handbook\%20of\%20Urban\%20Statistics\%202019.pdf.

Gopinath, G. (2020). The great lockdown: worst economic downturn since the great depression. Retrieved May 20, 2020, from https://blogs.imf.org/2020/04/14/the-great-lockdown-worst-economic-downturnsince-the-great-depression/.

Goyal, K., Chauhan, P., Chhikara, K., Gupta, P., \& Singh, M. P. (2020). Fear of COVID 2019: First suicide case in India. Asian Journal of Psychiatry, 49, 101989. https://doi.org/10.1016/j.ajp.2020.101989.

Gupta, A., Banerjee, S., \& Das, S. (2020a). Significance of geographical factors to the COVID-19 outbreak in India. Modeling Earth System and Environment. https://doi.org/10.1007/s40808-020-00838-2.

Gupta, A., \& Pradhan, B. (2020). Impact of daily weather on COVID-19 outbreak in India. medRxiv. https ://doi.org/10.1101/2020.06.15.20131490.

Gupta, S., Raghuwanshi, G. S., \& Chanda, A. (2020b). Effect of weather on COVID-19 spread in the US: A prediction model for India in 2020. Science of the Total Environment, 728, 138860. https://doi. org/10.1016/j.ajp.2020.101989.

Harmooshi, N. N., Shirbandi, K., \& Rahim, F. (2020). Environmental concern regarding the effect of humidity and temperature on 2019-nCoV survival: Fact or fiction. Environmental Science and Pollution Research. https://doi.org/10.1007/s11356-020-09733-w.

Iqbal, M. M., Abid, I., Hussain, S., Shahzad, N., Waqas, M. S., \& Iqbal, M. J. (2020). The effects of regional climatic condition on the spread of COVID-19 at global scale. Science of the Total Environment, 739, 140101. https://doi.org/10.1016/j.scitotenv.2020.140101.

Islam, N., Shabnam, S., \& Erzurumluoglu, A. M. (2020). Temperature, humidity, and wind speed are associated with lower Covid-19 incidence. medRxiv. https://doi.org/10.1101/2020.03.27.20045658.

Kendall, M. G. (1975). Rank correlation methods, 4th ed. London, UK: Charles Griffin.

Kumar, P., Gulia, S., Harrison, R. M., \& Khare, M. (2017). The influence of odd-even car trial on fine and coarse particles in Delhi. Environmental Pollution, 225, 20-30. https://doi.org/10.1016/j.envpo 1.2017.03.017. 
Liu, W., Tao, Z. W., Lei, W., Yuan, M. L., Liu, K., Zhou, K., et al. (2020a). Analysis of factors associated with disease outcomes in hospitalized patients with 2019 novel coronavirus disease. Chinese Medical Journal (Engl), 133, 1032-1038. https://doi.org/10.1097\%2FCM9.0000000000000775.

Liu, J., Zhou, J., Yao, J., Zhang, X., Li, L., Xu, X., et al. (2020b). Impact of meteorological factors on the COVID-19 transmission: A multi-city study in China. Science of the Total Environment, 726, 138513. https://doi.org/10.1016/j.scitotenv.2020.138513.

Ma, Y., Zhao, Y., Liu, J., He, X., Wang, B., Fu, S., et al. (2020). Effects of temperature variation and humidity on the death of COVID-19 in Wuhan, China. Science of the Total Environment, 724, 138226. https://doi.org/10.1016/j.scitotenv.2020.138226.

Mahajan, P., \& Kaushal, J. (2020). Epidemic trend of COVID-19 transmission in India during lockdown-1 Phase. Journal of Community Health. https://doi.org/10.1007/s10900-020-00863-3.

Mann, H. B. (1945). Nonparametric tests against trend. Econometrica, 13, 245. https://doi. org/10.2307/1907187.

Manzak, D., \& Manzak, A. (2020). Analysis of environmental, economic, and demographic factors affecting Covid-19 transmission and associated deaths in the USA. SSRN. https://doi.org/10.2139/ ssrn.3644677.

Meraj, G., Farooq, M., Singh, S. K., Romshoo, S. A., Sudhanshu, Nathawat, M. S., et al. (2020). Coronavirus pandemic versus temperature in the context of Indian subcontinent: A preliminary statistical analysis. Environment, Development and Sustainability. https://doi.org/10.1007/s10668-020-00854 -3 .

Minhas, S. (2020). Could India be the origin of next COVID-19 like epidemic? Science of the Total Environment, 728, 138918. https://doi.org/10.1016/J.scitotenv.2020.138918.

Núñez-Delgado, A. (2020). What do we know about the SARS-CoV-2 coronavirus in the environment? Science of the Total Environment, 727, 138647. https://doi.org/10.1016/j.scitotenv.2020.138647.

Oliveiros, B., Caramelo, L., Ferreira, N. C., \& Caramelo, F. (2020). Role of temperature and humidity in the modulation of the doubling time of COVID-19 cases. medRxiv. https://doi. org/10.1101/2020.03.05.20031872.

Perrino, C., Tiwari, S., Catrambone, M., Torre, S. D., Rantica, E., \& Canepari, S. (2011). Chemical characterization of atmospheric PM in Delhi, India, during different periods of the year including Diwali festival. Atmospheric Pollution Research, 2, 418-427. https://doi.org/10.5094/APR.2011.048.

Prata, D. N., Rodrigues, W., \& Bermejo, P. H. (2020). Temperature significantly changes COVID-19 transmission in (sub) tropical cities of Brazil. Science of the Total Environment, 729, 138862. https ://doi.org/10.1016/j.scitotenv.2020.138862.

Raina, S. K., Kumar, R., Bhota, S., Gupta, G., Kumar, D., Chauhan, R., et al. (2020). Does temperature and humidity influence the spread of COVID-19? A preliminary report. Journal of Family Medicine and Primary Care, 9, 1811-1814.

Roy, M. P. (2020). Temperature and COVID-19: India. BMJ Journals. https://doi.org/10.1136/bmjeb m-2020-111459.

Sahin, M. (2020). Impact of weather on COVID-19 pandemic in Turkey. Science of the Total Environment, 728, 138810. https://doi.org/10.1016/j.scitotenv.2020.138810.

Sajadi, M. M., Habibzadeh, P., Vintzileos, A., Shokouhi, S., Miralles-Wilhelm, F., \& Amoroso, A. (2020). Temperature and latitude analysis to predict potential spread and seasonality for COVID19. SSRN. https://doi.org/10.2139/ssrn.3550308.

Sannigrahi, S., Pilla, F., Basu, B., Basu, A. S., \& Molter, A. (2020). Examining the association between socio-demographic composition and COVID-19 fatalities in the European region using spatial regression approach. Sustainable Cities and Society, 62, 102418. https://doi.org/10.1016/j. scs.2020.102418.

Sarmadi, M., Maruf, N., \& Moghaddam, V. K. (2020). Association of COVID-19 global distribution and environmental and demographic factors. Environmental Research, 188, 109748. https://doi. org/10.1016/j.envres.2020.109748.

Scafetta, N. (2020). A proposal for isotherm world maps to forecast the seasonal evolution of the SARSCoV-2 pandemic. https://doi.org/10.20944/preprints202004.0063.v1.

Sen, P. K. (1968). Estimates of the regression coefficient based on Kendall's Tau. Journal of the American Statistical Association, 63, 1379-1389. https://doi.org/10.1080/01621459.1968.10480934.

Shahzad, K., Shahzad, Z., Iqbal, N., Shahzad, F., \& Fareed, Z. (2020). Effects of climatological parameters on the outbreak spread of COVID-19 in highly affected regions of Spain. Preprint Research Square. https://doi.org/10.21203/rs.3.rs-30377/v1.

Shi, P., Dong, Y., Yan, H., Zhao, C., Li, X., Liu, W., et al. (2020). Impact of temperature on the dynamics of the COVID-19 outbreak in China. Science of the Total Environment, 728, 138890. https://doi. org/10.1016/j.scitotenv.2020.138890. 
Singh, K. K., \& Shukla, S. (2005). Profiling "Informal City" of Delhi. Policies, Norms, Institutions \& Scope of Intervention. WaterAid India and Delhi Slum Dwellers Federation. https://washmatters.wateraid. org/publications/profiling-informal-city-of-delhi-2005.

Tosepu, R., Gunawan, J., Effendy, D. S., Ahmad, L. O. A. I., Lestari, H., Bahar, H., et al. (2020). Correlation between weather and Covid-19 pandemic in Jakarta, Indonesia. Science of the Total Environment, 725, 138436. https://doi.org/10.1016/J.scitotenv.2020.138436.

Ujiie, M., Tsuzuki, S., \& Ohmagari, N. (2020). Effect of temperature on the infectivity of COVID-19. International Journal of Infectious Diseases, 95, 301-303. https://doi.org/10.1016/j.ijid.2020.04.068.

Vardavas, C. I., \& Nikitara, K. (2020). COVID-19 and smoking: A systematic review of the evidence. Tobacco Induced Disease, 18, 20. https://doi.org/10.18332\%2Ftid\%2F119324.

Verity, R., et al. (2020). Estimates of the severity of coronavirus disease 2019: A model-based analysis. Lancet Infectious Disease, 20, 669-677. https://doi.org/10.1016/S1473-3099(20)30243-7.

Vinoj, V., Gopinath, N., Landu, K., Behera, B., \& Mishra, B. (2020). The COVID-19 spread in India and its dependence on temperature and relative humidity. Preprints, 2020, 2020070082. https://doi. org/10.20944/preprints202007.0082.v1.

Wang, M., Jiang, A., Gong, L., Luo, L., Guo, W., Li, C., Zheng, J., Li, C., Yang, B., Zeng, J., Chen, Y., Zheng, K., \& Li, H. (2020a). Temperature significant change COVID-19 transmission in 429 cities. medRxiv. https://doi.org/10.1101/2020.02.22.200257912020.2002.2022.20025791.

Wang, J., Tang, K., Feng, K., \& Lv, W. (2020b). High temperature and high humidity reduce the transmission of COVID-19. SSRN. https://ssrn.com/abstract=3551767.

WHO. (2020). Coronavirus disease: What you need to know? Retrieved 19 May, 2020, from https://www. afro.who.int/news/coronavirus-disease-what-you-need-know.

Wu, Y., Jind, W., Liu, J., Ma, Q., Yuan, J., Wang, Y., et al. (2020). Effects of temperature and humidity on the daily new cases and new deaths of COVID-19 in 166 countries. Science of the Total Environment, 729, 139051. https://doi.org/10.1016/j.scitotenv.2020.139051.

Xie, Z., \& Li D. (2020). Health and demographic impact on COVID-19 infection and mortality in US Counties. medRxiv. https://doi.org/10.1101/2020.05.06.20093195.

Xie, J., \& Zhu, Y. (2020). Association between ambient temperature and COVID-19 infection in 122 cities from China. Science of the Total Environment, 724, 138201. https://doi.org/10.1016/j.scito tenv.2020.138201.

Yao, Y., Pan, J., Liu, Z., Meng, X., Wang, W., Kan, H., et al. (2020). No association of COVID-19 transmission with temperature or UV radiation in Chinese cities. European Respiratory Journal, 55, 2000517. https://doi.org/10.1183/13993003.00517-2020.

Yuan, S., Jiang, S. C., \& Li, Z. L. (2020). Do humidity and temperature impact the spread of the novel coronavirus? Frontiers in Public Health, 8, 240. https://doi.org/10.3389/fpubh.2020.00240.

Zhu, N., Zhang, D., Wang, W., Li, X., Yang, B., \& Song, J. (2020). A novel coronavirus from patients with pneumonia in China, 2019. New England Journal of Medicine, 382, 727-733. https://doi.org/10.1056/ NEJMoa2001017.

Publisher's Note Springer Nature remains neutral with regard to jurisdictional claims in published maps and institutional affiliations.

\section{Affiliations}

\section{Omvir Singh ${ }^{1}$ (D) Pankaj Bhardwaj ${ }^{2} \cdot$ Dinesh Kumar $^{3}$}

Pankaj Bhardwaj

pkbhardwaj007@gmail.com

Dinesh Kumar

dineshgeo87@gmail.com

1 Department of Geography, Kurukshetra University, Kurukshetra 136119, India

2 Department of Geography, Government College, Bahu, Jhajjar 124142, India

3 Department of Geography, Government College for Women, Gohana 131301, India 